Article

\title{
A Novel High Sensitivity Sensor for Remote Field Eddy Current Non-Destructive Testing Based on Orthogonal Magnetic Field
}

\author{
Xiaojie Xu ${ }^{1, *}$, Ming Liu ${ }^{1}$, Zhanbin Zhang ${ }^{1}$ and Yueling Jia ${ }^{2}$ \\ 1 School of Information and Navigation, Air Force Engineering University, Xi'an 710077, China; \\ E-Mails: 1ming0601@163.com (M.L.); zzbin@163.com (Z.Z.) \\ 2 School of Equipment Management and Safety Engineering, Air Force Engineering University, \\ Xi'an 710077, China; E-Mail: jyl1974@126.com \\ * Author to whom correspondence should be addressed; E-Mail: dr_xxj@163.com; \\ Tel.: +86-29-8479-1511; Fax: +86-29-8428-3724.
}

External Editor: Thomas Schumacher

Received: 17 September 2014; in revised form: 28 November 2014 / Accepted: 1 December 2014 / Published: 12 December 2014

\begin{abstract}
Remote field eddy current is an effective non-destructive testing method for ferromagnetic tubular structures. In view of conventional sensors' disadvantages such as low signal-to-noise ratio and poor sensitivity to axial cracks, a novel high sensitivity sensor based on orthogonal magnetic field excitation is proposed. Firstly, through a three-dimensional finite element simulation, the remote field effect under orthogonal magnetic field excitation is determined, and an appropriate configuration which can generate an orthogonal magnetic field for a tubular structure is developed. Secondly, optimized selection of key parameters such as frequency, exciting currents and shielding modes is analyzed in detail, and different types of pick-up coils, including a new self-differential mode pick-up coil, are designed and analyzed. Lastly, the proposed sensor is verified experimentally by various types of defects manufactured on a section of a ferromagnetic tube. Experimental results show that the proposed novel sensor can largely improve the sensitivity of defect detection, especially for axial crack whose depth is less than $40 \%$ wall thickness, which are very difficult to detect and identify by conventional sensors. Another noteworthy advantage of the proposed sensor is that it has almost equal sensitivity to various types of defects, when a self-differential mode pick-up coil is adopted.
\end{abstract}


Keywords: non-destructive testing; remote field eddy current; sensor; orthogonal magnetic field; finite element simulation

\section{Introduction}

Eddy current testing is one of the most extensively used non-destructive testing (NDT) methods for conductive materials [1]. Remote field eddy current (RFEC) is a type of eddy current NDT, and has drawn more and more attention in the nondestructive testing of ferromagnetic tubular structures. RFEC has remarkable advantages such as almost equal sensitivity to inner and outer defects, easy defect characterization and insensitivity to lift-off or wobble [2]. Remote field eddy current testing mainly depends on indirect-coupled electromagnetic energy, which passes through a pipe wall twice, as shown in Figure 1.

Figure 1. Principle of remote field eddy current testing.

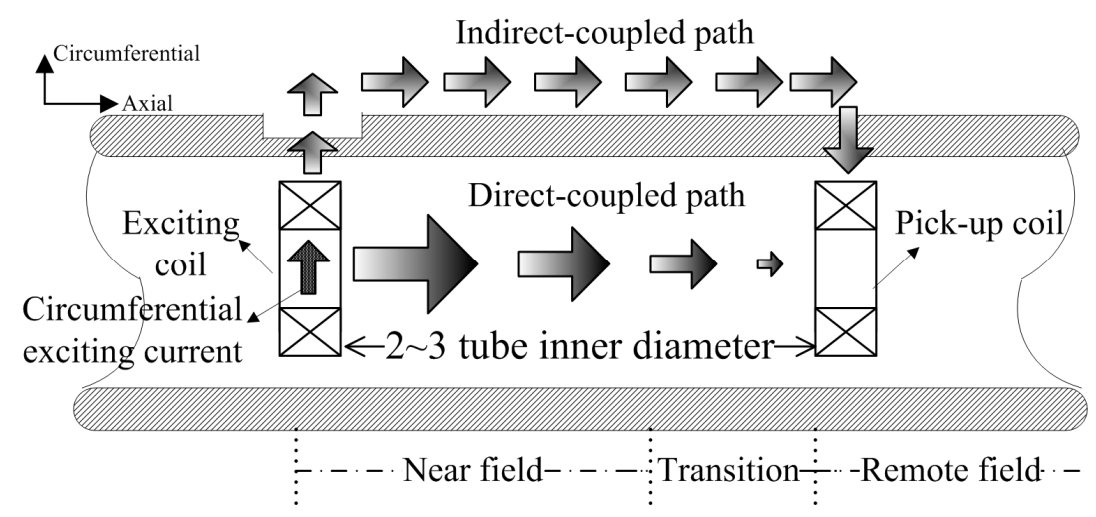

Detection sensitivity of RFEC testing, defined as the signal variation caused by a defect relative to a defect free sample, largely depends on the performance of its sensor. A conventional sensor uses a solenoid as an exciting coil and another co-axial solenoid $2 \sim 3$ tube inner diameters away as a pick-up coil. When the conventional sensor is used for ferromagnetic structures testing, it has disadvantages such as low signal-to-noise ratio (SNR) and poor sensitivity to axial cracks. Low SNR can be overcome by advanced signal detection and processing technology, for example, by using a lock-in amplifier to improve the weak signal detection ability and a homomorphic filter to eliminate the influence of nonlinear noise such as a magnetic perturbation [3]. However, its poor sensitivity to axial cracks is not easy to solve, because a conventional sensor only provides an axial magnetic field, which is more sensitive to a circumferential crack than an axial cracks. Some people try to solve it by using an appropriate pick-up coil to detect the weak electromagnetic field perturbation, such as differential modes and radial field pick-up coils [4]. On the other hand, some try to change the direction of the excitation to generate a specified electromagnetic field, for example, charging electricity directly on the tube wall to generate circumferential magnetic field [5], using an induction motor as excitation to detect stress corrosion cracks [6] and an inclined exciting coil to detect cracks in different directions [7]. Until now, how to design a sensor with appropriate exciting coils and pick-up coils is still critical to the sensitivity improvement of remote field eddy current testing. This article aims to 
demonstrate a remote field effect under orthogonal magnetic field excitation and design a novel sensor based on it.

\section{Orthogonal Magnetic Field for Tubular Structures}

\subsection{Principle of the Orthogonal Magnetic Field}

In conventional eddy current testing, orthogonal magnetic field excitation is proposed to inspect tabular structures. Two windings are located on the perpendicular plan of a rectangular frame, and the two windings are excited respectively by a sinusoid with the same frequency but quadrature lagging, and thus the magnetic fields generated by the two windings are oriented at $90^{\circ}$ to each other-called orthogonal magnetic field excitation [8].

The magnetic flux density generated by the two windings can be described as follows:

$$
\begin{aligned}
& B_{x}=A_{1} \sin \left(\omega t+\varphi_{0}\right) \\
& B_{y}=A_{2} \cos \left(\omega t+\varphi_{0}\right)
\end{aligned}
$$

where $A_{1}$ and $A_{2}$ are the amplitude of magnetic flux density, $\omega$ is the exciting frequency and $\varphi_{0}$ is the initial phase. $\mathrm{B}_{\mathrm{x}}$ and $\mathrm{B}_{\mathrm{y}}$ meet the elliptic equation:

$$
\frac{B_{x}{ }^{2}}{A_{1}{ }^{2}}+\frac{B_{y}{ }^{2}}{A_{2}{ }^{2}}=\sin \left(\omega t+\varphi_{0}\right)^{2}+\cos \left(\omega t+\varphi_{0}\right)^{2}=1
$$

When $\mathrm{A}_{1}=\mathrm{A}_{2}=\mathrm{A}$, Equation (3) can be simplified to a standard circular equation, and the combined magnetic flux density can be calculated by:

$$
\begin{gathered}
A M P_{B}=\sqrt{A^{2} \sin ^{2}\left(\omega t+\varphi_{0}\right)+A^{2} \cos ^{2}\left(\omega t+\varphi_{0}\right)}=\mathrm{A} \\
\text { Phase }_{B}=\operatorname{atan}\left(B_{x} / B_{y}\right)=\operatorname{atan}\left(\sin \left(\omega t+\varphi_{0}\right) / \cos \left(\omega t+\varphi_{0}\right)\right) \\
=\operatorname{atan}(\tan (\omega t+\varphi))=\left(\omega t+\varphi_{0}\right)
\end{gathered}
$$

From Equations (4) and (5), the strength of the combined magnetic field is constant and its direction rotates with time periodically. According to the Maxwell equation $\dot{J}=\nabla \times \dot{H}$, the eddy current induced in the specimen follows the same rule. Owing to its rotating characteristics, the above-mentioned orthogonal magnetic field excitation is proved to be sensitive enough to cracks in different directions.

The abovementioned coil mainly relies on a rectangular frame, and is not suitable for tubular structures because of the big air gap between the windings and tube wall. In [9-11], the authors propose a new exciting coil with three orthogonal coils making a $2 \pi / 3$ angle between and claim its remote field effect. In [5], the authors researched the remote field effect under circumferential magnetic field excitation by charging electricity directly on the tube wall, and claim an improvement of detection sensitivity to axial cracks. Considering the advantages of the abovementioned methods, the orthogonal pattern combined with axial magnetic field and circumferential magnetic field should be appropriate for the RFEC testing of tubular structures, with minimum modification of conventional sensors to get high sensitivity to different types of defects. 


\subsection{Finite Element Simulation}

Three-dimensional finite element method (FEM) is an effective simulation tool for eddy current NDT [12-16], and is adopted to verify the applicability of the proposed orthogonal magnetic field excitation pattern combined with axial magnetic field and circumferential magnetic field. Table 1 shows the simulation conditions.

Table 1. Simulation conditions.

\begin{tabular}{lcc}
\hline Model & Parameter & Value \\
\hline \multirow{4}{*}{ Tube } & Outer diameter & $82 \mathrm{~mm}$ \\
& Inner diameter & $70 \mathrm{~mm}$ \\
& Wall thickness & $6 \mathrm{~mm}$ \\
& Relative permeability & 329.5 \\
& Conductivity & $0.5 \times 10^{7} \mathrm{~S} / \mathrm{m}$ \\
\multirow{2}{*}{ Sensor } & Axial current density & $8.2 \times 10^{6} \mathrm{~A} / \mathrm{m}^{2}$ \\
& Circumferential current density & $1.6 \times 10^{6} \mathrm{~A} / \mathrm{m}^{2}$ \\
& Axial current waveform & Sinusoid, frequency $30 \mathrm{~Hz}$ and phase $0^{\circ}$ \\
& Circumferential current waveform & Sinusoid, frequency $30 \mathrm{~Hz}$ and phase $90^{\circ}$ \\
\cline { 2 - 3 } Defect & Direction & Axial and circumferential \\
& Size & Length $10 \mathrm{~mm}$, width $0.5 \mathrm{~mm}$ and depth $1.8 \mathrm{~mm}$ \\
& Location & $246 \mathrm{~mm}$ away from exciting coil \\
\hline
\end{tabular}

Figure 2 shows the simulation models of the exciting coil. Figure $2 \mathrm{a}$ shows finite element mesh of the conventional solenoid exciting coil, while Figure $2 b$ shows the circumferential current density applied on the coil, which is used to generate axial magnetic field. Figure $2 \mathrm{c}$ shows the finite element mesh of a metal cylinder located inside the conventional solenoid, while Figure $2 \mathrm{~d}$ shows the axial current density applied on the metal cylinder, which is used to generate a circumferential magnetic field.

Figure 2. (a) Solenoid exciting coil; (b) Circumferential current density; (c) Metal cylinder; (d) Axial current density.

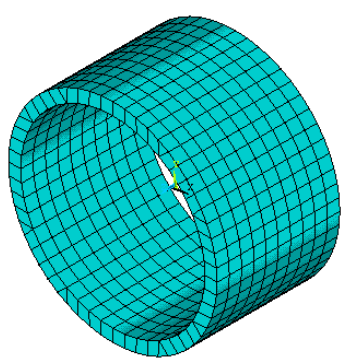

(a)

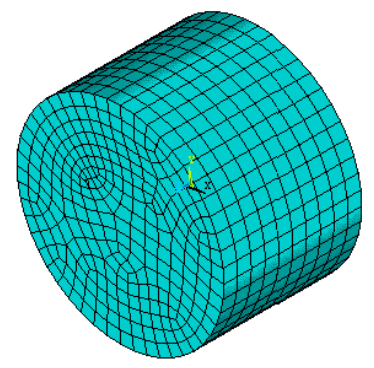

(c)

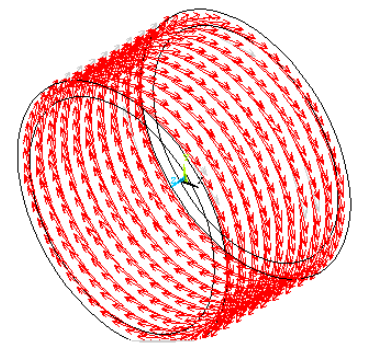

(b)

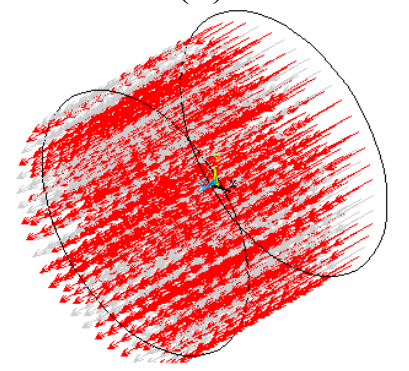

(d) 
Figure 3 shows the real part and imaginary part of spatial magnetic flux density, and the two parts correspond to axial magnetic field excitation and circumferential magnetic field excitation. The axial magnetic flux density (near field is $0.206528 \mathrm{mT}$, and remote field is $0.094255 \mathrm{mT}$ ) and circumferential magnetic flux density (near field is $0.1982 \mathrm{mT}$, and remote field is $0.088772 \mathrm{mT}$ ) are almost the same, indicating that the simulation models and parameters are suitable for generating almost equal axial magnetic field and circumferential magnetic field.

Figure 3. (a) Real part of magnetic flux density; (b) Imaginary part of magnetic flux density.

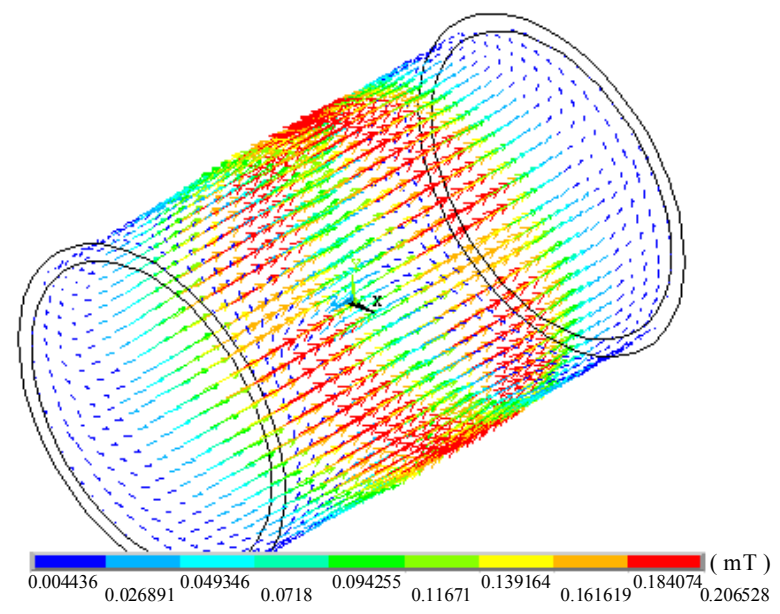

(a)

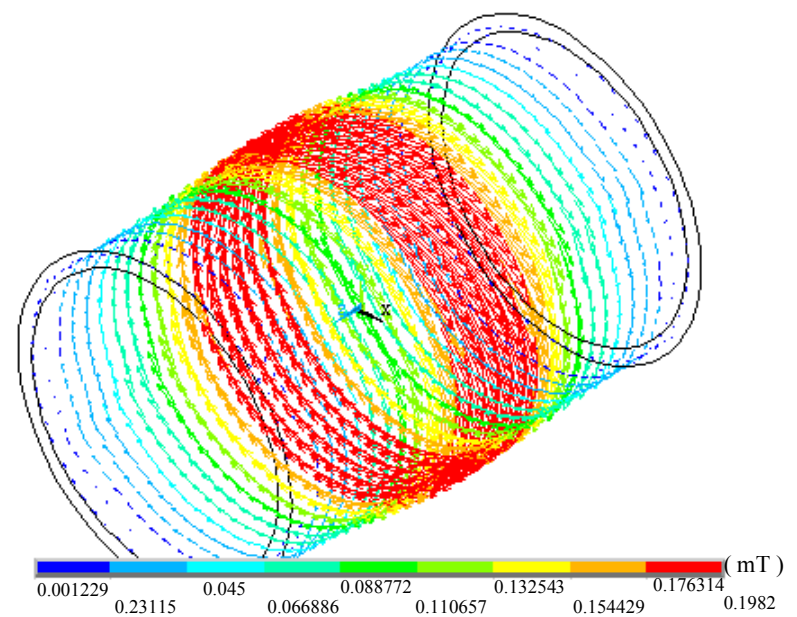

(b)

Figure 4 shows periodic changes of magnetic flux density direction at a fixed point in the remote field zone. The variation rule is very similar to the orthogonal magnetic field under a rectangular frame, which means that the remote field effect is still valid under a combination of axial magnetic field excitation and circumferential magnetic field excitation.

Figure 4. Changes of magnetic flux density direction.

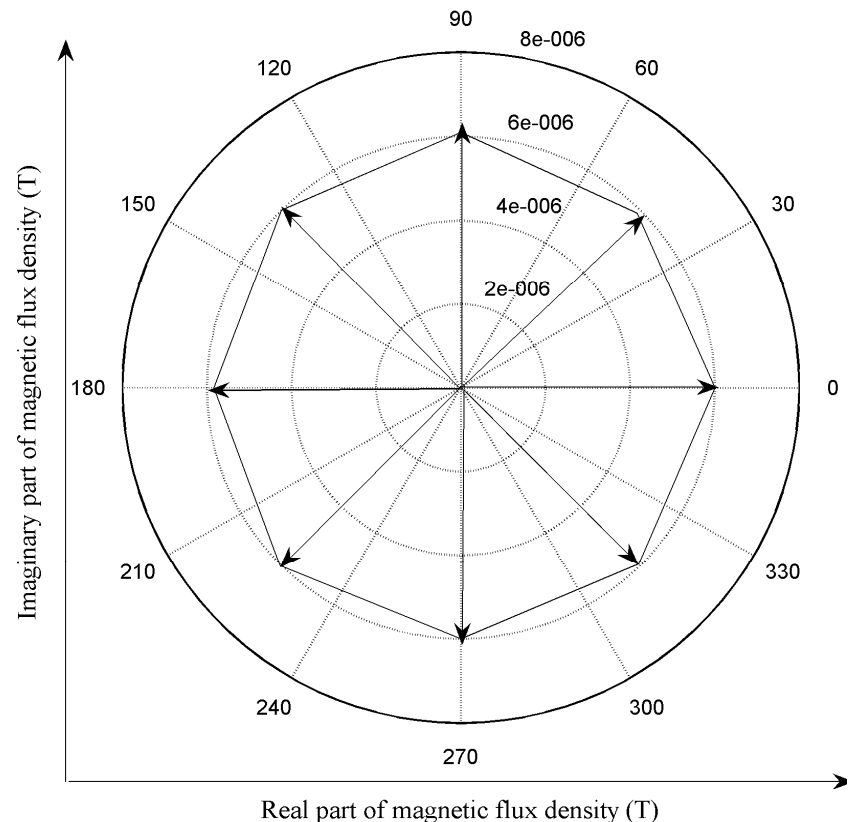




\subsection{Comparison of Conventional Axial Field Excitation and Orthogonal Field Excitation}

To facilitate the analysis, a perturbation field computed by the "anomalous source" method is used, which means removing the defect free background field from the computed field when there is a defect [17]. Firstly, the crack detection ability of the conventional exciting coil is simulated and the radial perturbation fields around the axial and circumferential crack are shown in Figure 5. The perturbation caused by the circumferential crack $\left(3.0 \times 10^{-5} \mathrm{~T}\right)$ is even thirty three times higher than with the axial crack $\left(0.9 \times 10^{-6} \mathrm{~T}\right)$. The simulation result can be used to interpret the poor detection sensitivity to axial cracks.

Figure 5. Perturbation field caused by (a) Circumferential crack; (b) Axial crack.

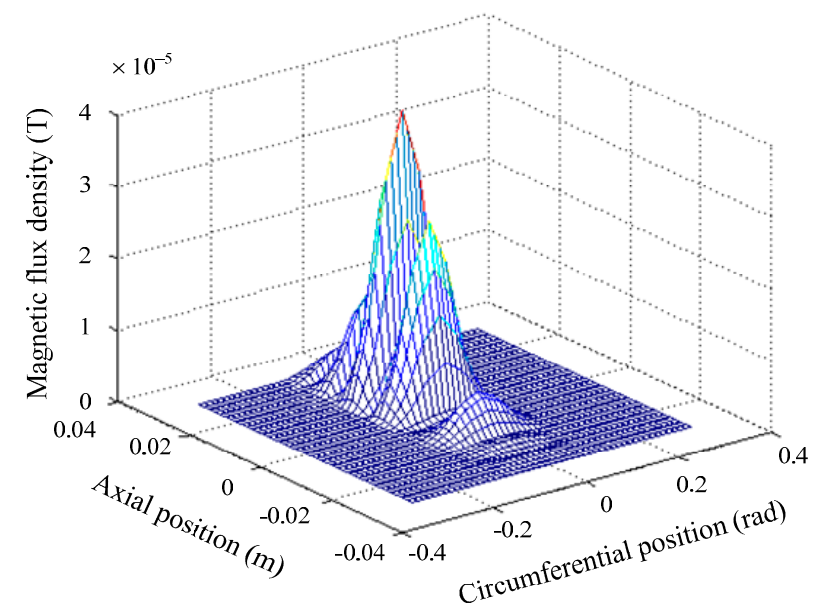

(a)

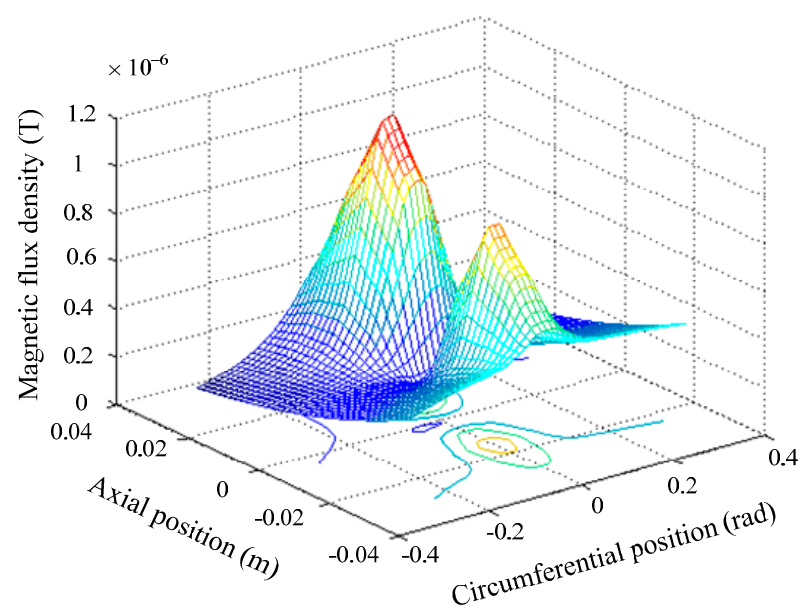

(b)

Secondly, the crack detection ability of the proposed orthogonal magnetic field excitation is simulated and radial perturbation field around the axial and circumferential crack are shown in Figure 6 . The perturbation caused by the circumferential crack $\left(1.3 \times 10^{-5} \mathrm{~T}\right)$ is almost the same as that by the axial crack $\left(1.38 \times 10^{-5} \mathrm{~T}\right)$, which means the proposed exciting coil can achieve high sensitivity to cracks in different directions.

Figure 6. Perturbation field caused by (a) Circumferential crack; (b) Axial crack.

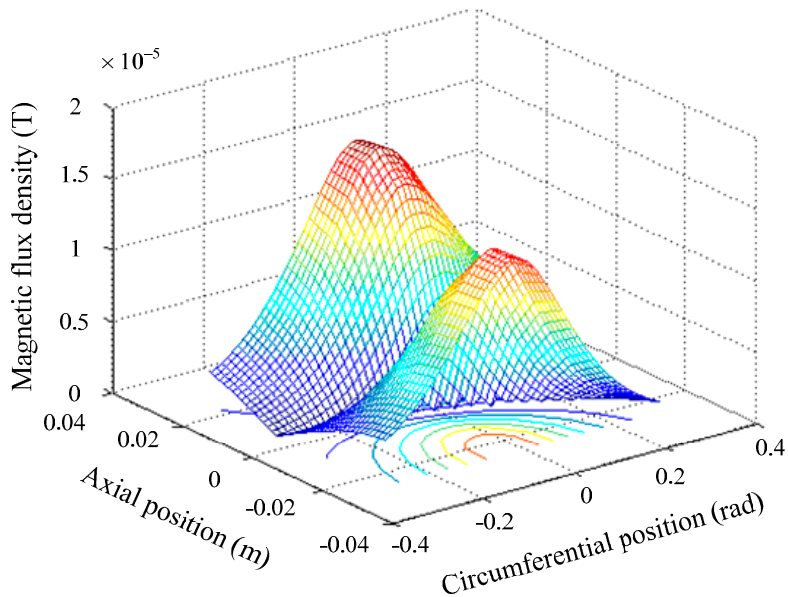

(a)

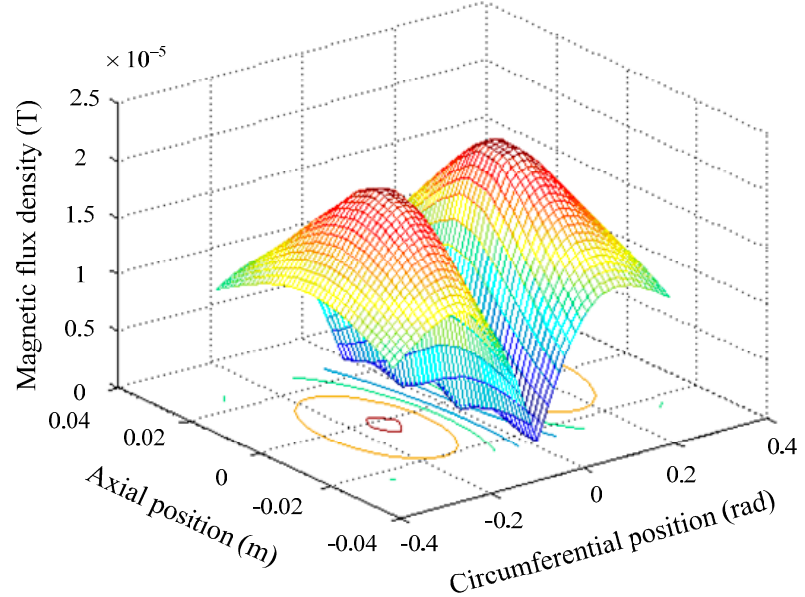

(b) 


\section{Novel Sensor Design}

Figure 7 shows the composition of the proposed novel sensor. The sensor consists of an exciting coil, a centering device, and different types of pick-up coils, an adjustable base, an adjusting screw and a shielding facility. The exciting coil is used to obtain the orthogonal magnetic field, and the centering device to control the sensor's wobble or off-center movement. The pick-up coils of different types with an adjustable base are used to detect different components of the magnetic field perturbation. The adjusting screw is used to set a proper distance between the exciting coil and pick-up coil. The shielding facility is used to prevent the direct-coupled magnetic field from entering the pick-up coil, and thus reduce the sensor's length.

Figure 7. Composition of proposed novel sensor.

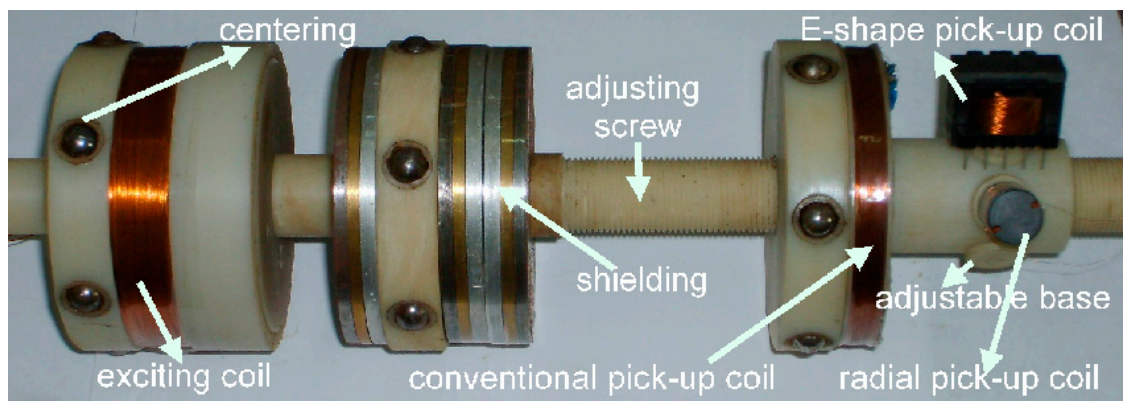

\subsection{Exciting Coil Design}

Once another coil which can obtain circumferential magnetic field is designed and combined with the existing solenoid coil, the orthogonal magnetic field will be obtained. Figure 8 shows the interior of the exciting coil, and three possible configurations which can generate the orthogonal magnetic field for tubular structures are shown in Figure $8 \mathrm{a}-\mathrm{c}$, respectively.

Figure 8. (a) Configuration 1; (b) Configuration 2; (c) Configuration 3.

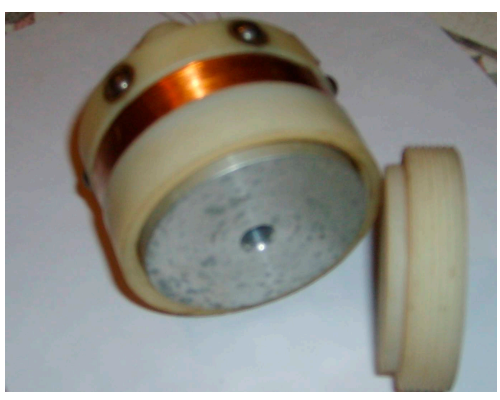

(a)

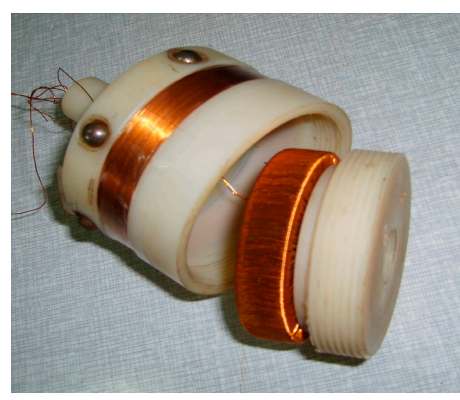

(b)

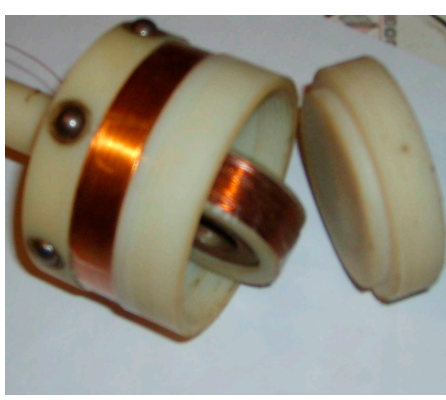

(c)

Configuration 1 adds a coaxial cylindrical conductor inside a conventional solenoid, as shown in Figure 8a. When an AC current is applied between two ends of the cylindrical conductor, due to the skin effect, the current will be collected on the surface $[18,19]$, and then the circumferential magnetic field will be obtained.

Configuration 2 adds a spiral coil inside a conventional solenoid, as shown in Figure 8 b. According to the right-hand rule, a circumferential magnetic field will be obtained. Although the 
circumferential magnetic field will be restricted in the magnetic core in ideal conditions in accordance with Ampere's circuit theorem, some circumferential magnetic flux will leak to the surrounding air, as the ferromagnetic tube wall can serve as another magnetic path [20].

Configuration 3 adds a solenoid which is perpendicular to a conventional solenoid, as shown in Figure 8c. According to the right-hand rule, a radial magnetic field will be obtained. Some of the radial magnetic field will propagate along the circumferential surface of the tube, as the ferromagnetic tube wall can serve as another magnetic path.

Two important phenomena of remote field eddy current testing: the "magnetic potential canyon" which means the transition zone where fast signal attenuation changes to slow signal attenuation, and "phase knot" which means the phase difference between a near field and a remote field, are used for the comparison of the three configurations mentioned above. Figure 9 shows "pull experiment" results, which are achieved by taking the pick-up coil away from the exciting coil step by step. The "magnetic potential canyon" and "phase knot" phenomena can be observed clearly when the first and second configuration (i.e., Configurations 1 and 2) is used, but the third configuration failed. Finally, the first configuration is considered as the most appropriate one, because the remote field zone is relatively closer to the exciting coil (3 tube inner diameter) than the second (3.8 tube inner diameter), which means a shorter sensor can be designed.

Figure 9. Comparison results of three configurations.
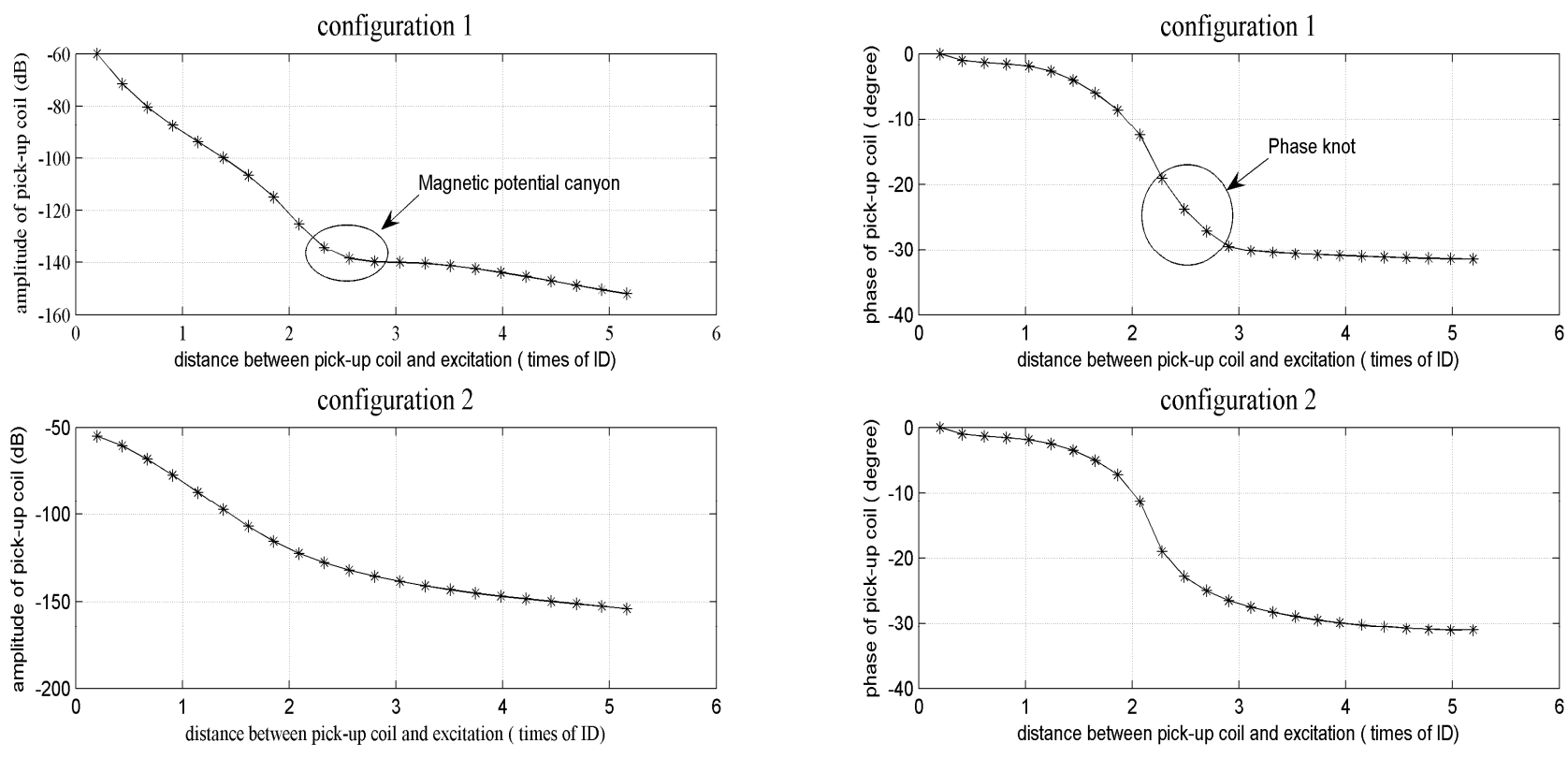

configuration 3
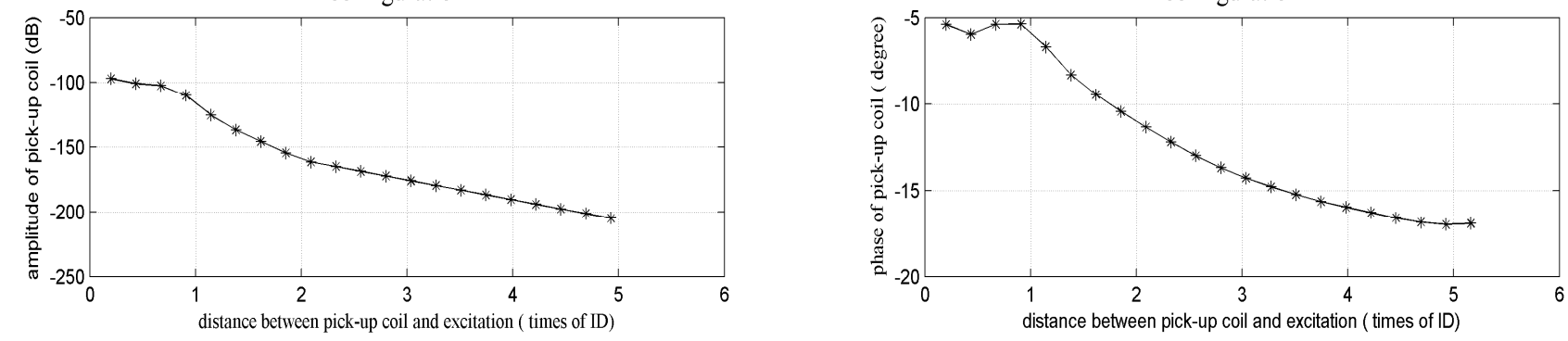


\subsection{Pick-Up Coil Design}

\subsubsection{Differential Mode}

Because the remote field eddy current is a relatively weak signal system, a differential mode pick-up coil is usually used to improve the detection sensitivity [21,22]. Adopting two rod-shape pick-up coils is the most popular differential mode used for eddy current nondestructive testing. The differential of output signals of two windings can improve the detection sensitivity, however, it is susceptible to wobble or off-center movement. At the same time, it is difficult to ensure uniformity of the two windings. Two U-shape pick-up coils, which use two windings warped on two "face to face" U-shape magnetic cores, can reduce the influence of wobble or off-center movement, for the two windings sharing same magnetic paths. Yet, it is still difficult to deal with the uniformity of the two windings.

A pick-up coil with an E-shape magnetic core shown in Figure 10 is a new differential mode, which was first proposed to detect cracks in aircraft multilayer structures [23], and is called "self-differential". The pick-up coil is wound on the central axis of the E-shape magnetic core, as shown in Figure $10 \mathrm{a}-\mathrm{c}$ which shows its principle. In the symmetric case which is defect-free, there is no magnetic flux that enters the central axis, because the magnetic flux always follows the path which has minimum reluctance in accordance with magnetic path theory. When one of the side shafts passes through a defect, the symmetry will be broken because of the stronger magnetic field intensity around the defect, and then a part of magnetic flux will enter the central axis from the bottom to the top and is picked up by the winding. When another side shaft passes through a defect, a part of magnetic flux will enter the central axis from the opposite direction. Figure 11 shows the simulation results. Figure 11a displays the magnetic field distribution when one side shaft passes through crack, and the direction of magnetic flux in the central axis is from the bottom to the top. Figure $11 \mathrm{~b}$ displays the magnetic field distribution when another side shaft passes through a crack, and the direction of the magnetic flux in central axis is from the top to the bottom.

Figure 10. Self-differential mode (a) Pick-up coil; (b) E-shape magnetic core; (c) Principle.

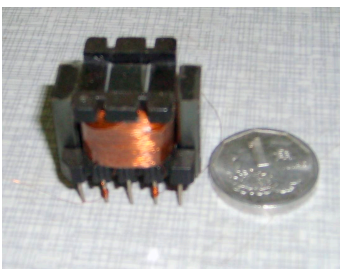

(a)

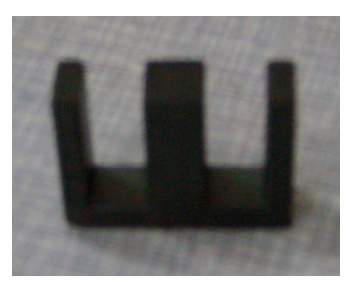

(b)

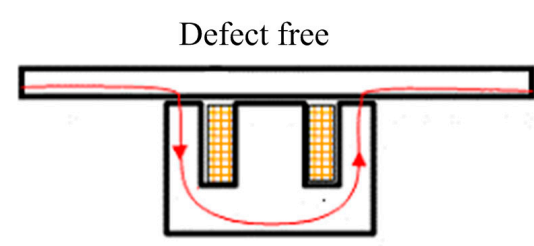

One side shaft pass through crack

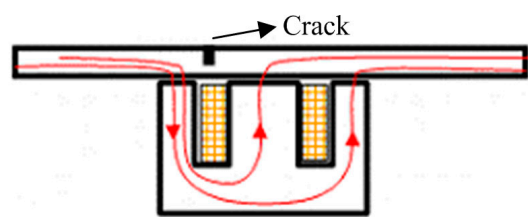

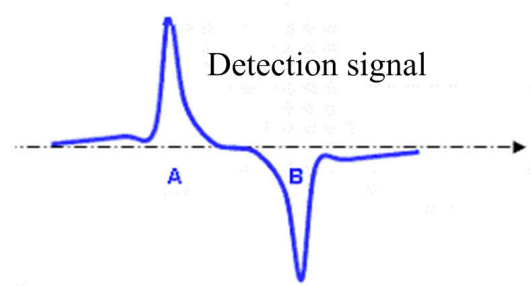

Another side shaft pass through crack

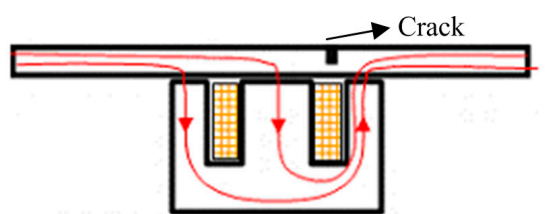

(c) 
Figure 11. (a) One side shaft pass through crack; (b) Another side shaft pass through crack.

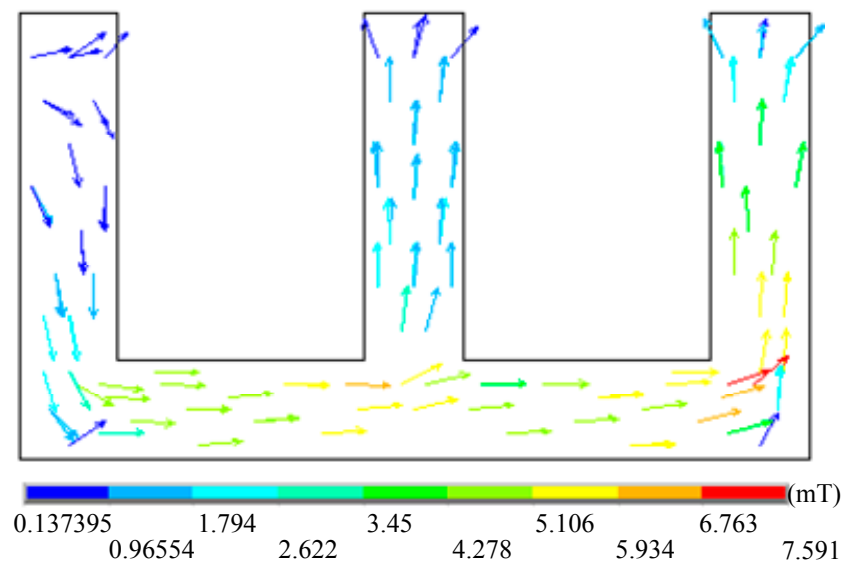

(a)

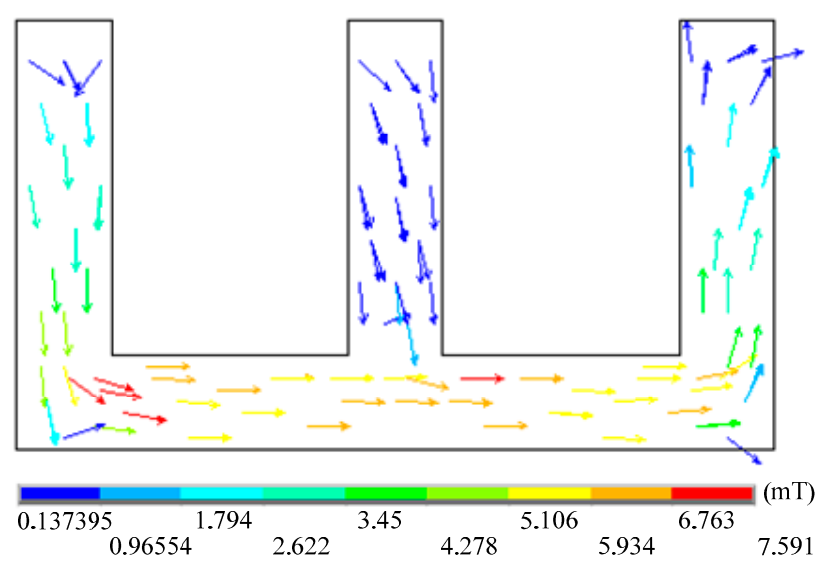

(b)

\subsubsection{Conventional Pick-Up Coil, Circumferential and Radial Field Pick-Up Coils}

Conventional pick-up coils and local pick-up coils which are sensitive to the circumferential field and radial field are also designed. Figure 12a shows the conventional pick-up coil, which is a co-axial solenoid. Figure $12 \mathrm{~b}$ shows the circumferential field pick-up coil based on a U-shape magnetic core. Figure 12c shows the radial field pick-up coil based on a rod-shape magnetic core. Figure $12 \mathrm{~d}$ shows their placement.

Figure 12. (a) Conventional pick-up coil; (b) Circumferential field pick-up coil; (c) Radial field pick-up coil; (d) Placement.

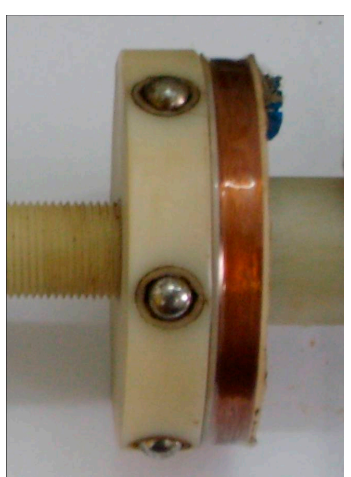

(a)

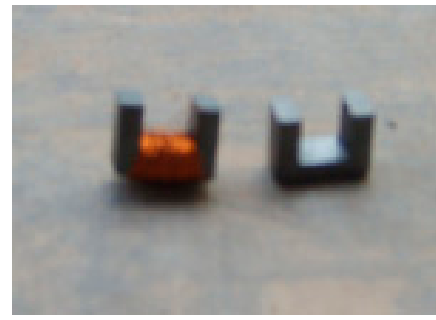

(b)

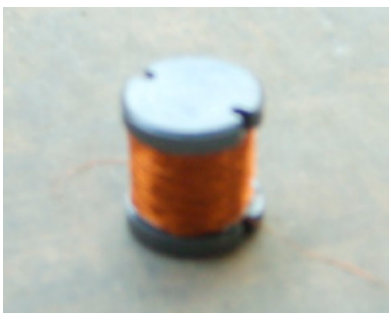

(c)

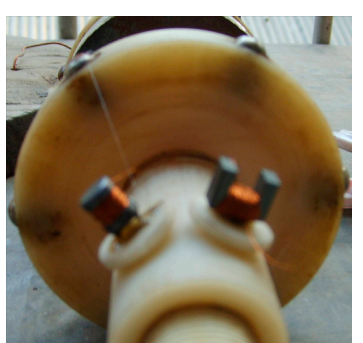

(d)

\subsection{Experimental System Design}

Figure 13 shows the schematic diagram and photography of the experimental system, which consists of orthogonal signal generation units, power amplifier units, power supply units, display units and signal acquisition and processing units. 
Figure 13. (a) Schematic diagram of experimental system; (b) Photograph of experimental system.

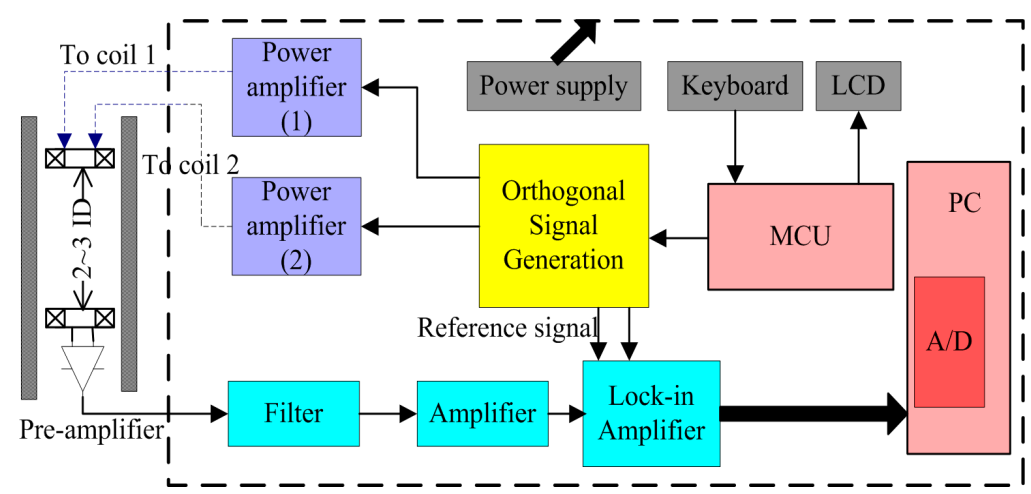

(a)

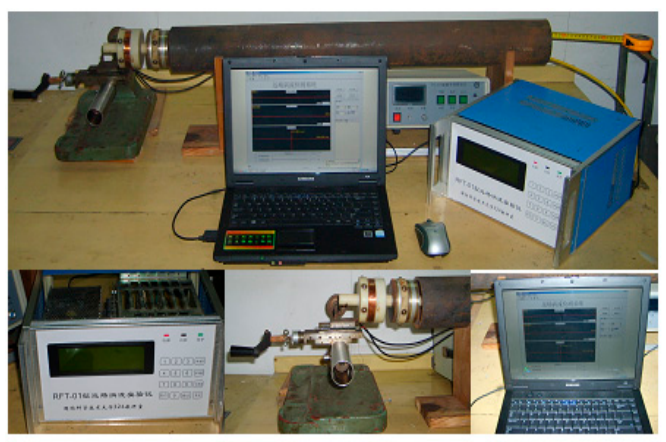

(b)

\subsection{Key Parameters Selection}

\subsubsection{Frequency}

Figure 14 shows RFEC characteristic curves under different frequency conditions (10, 30, 60, 120, 240 and $480 \mathrm{~Hz}$ ). When the frequency increases, the signal strength decreases rapidly, as shown in Figure 14a, because high frequency electromagnetic waves are attenuated dramatically when they pass through the tube wall twice. This is the reason why RFEC testing of ferromagnetic tubes is always done at frequencies below $60 \mathrm{~Hz}$. Figure 14b shows the phase difference between a remote field zone and a near zone. Except for the lowest frequency $(10 \mathrm{~Hz})$ and highest frequency $(480 \mathrm{~Hz})$, the "phase knot" effect can be clearly observed, and the maximum appears at $60 \mathrm{~Hz}$ (about $60^{\circ}$ phase difference), indicating that a frequency between 30 and $240 \mathrm{~Hz}$ can be appropriate. Finally, $60 \mathrm{~Hz}$ is selected as the exciting frequency, for proper signal strength and maximum phase difference which will be helpful for crack identification.

Figure 14. Characteristic curve under different frequency. (a) Amplitude; (b) Phase.

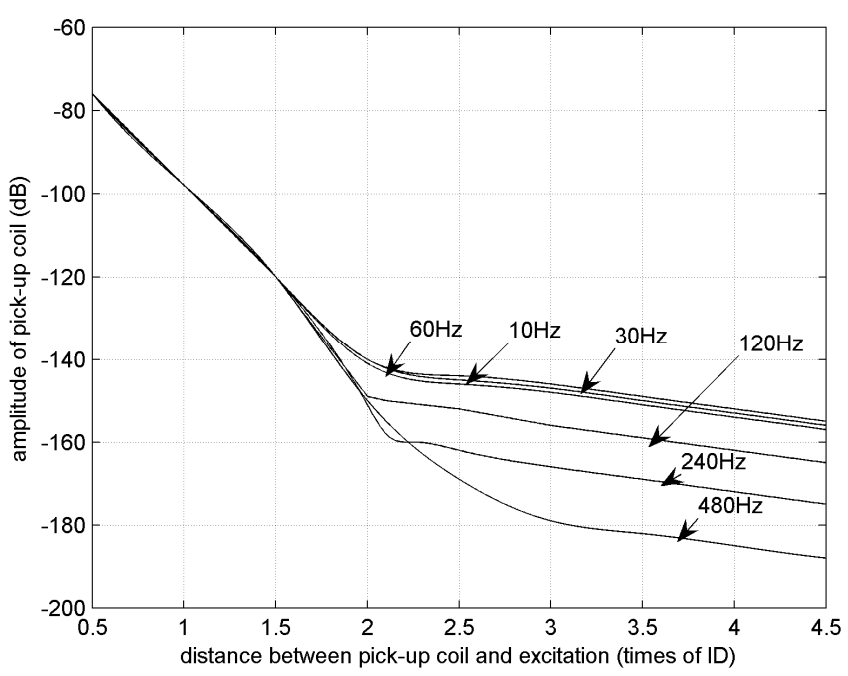

(a)

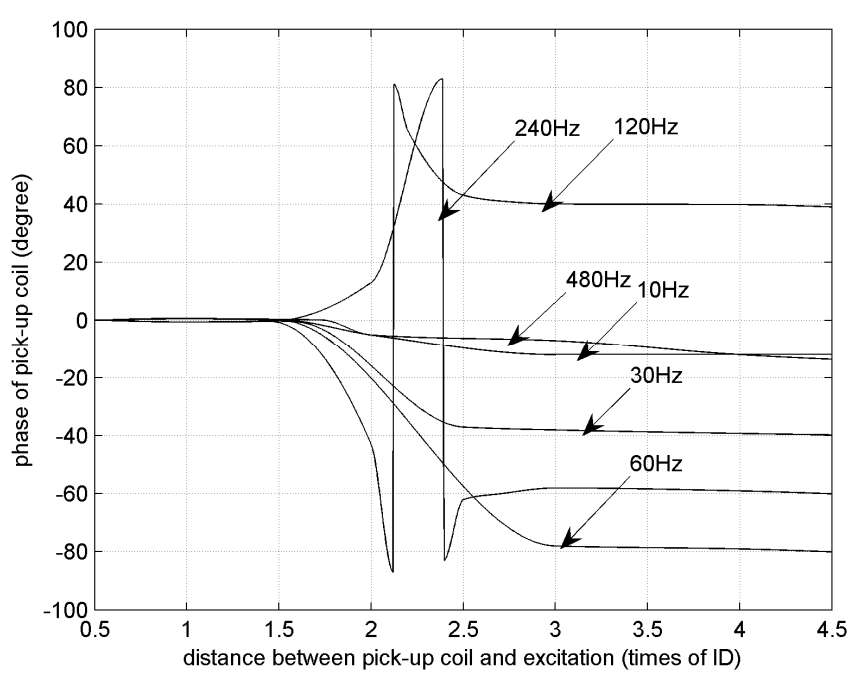

(b) 


\subsubsection{Exciting Current}

The remote field eddy current is a low energy transmission system, and the amplitude of a pick-up coil in the remote field zone usually has a few millivolts. An exciting current properly selected can increase the signal strength. Figure 15 shows the influence of different exciting currents.

The relationship between signal strength and exciting currents remains nearly linear in FEM simulation, as shown in Figure 15a. However in the experimental test, a nonlinear relationship appears when the exciting current increases to $1.4 \mathrm{~A}$ or more. In some cases, the signal strength even decreases with the increase of the exciting current, as shown in Figure 15b. This is perhaps because the ferromagnetic tube will enter the so-called Rayleigh region when the exciting current is high enough, and then the tube's permeability will increase. In view of RFEC testing's dependence on energy passing twice through the tube wall, the increasing permeability will reduce the energy coupled to the pick-up coil, and then decrease signal strength. Finally, the exciting current of the solenoid and cylindrical conductor is set at $1.1 \mathrm{~A}$ and $1.7 \mathrm{~A}$ respectively to ensure similar strength of the axial and circumferential field in a remote field zone.

Figure 15. Influence of exciting currents. (a) Simulation; (b) Experiment.

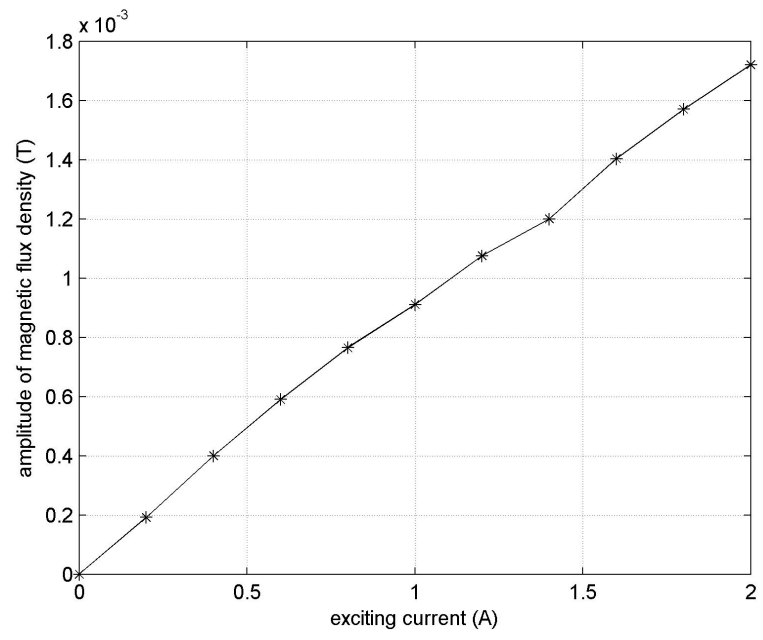

(a)

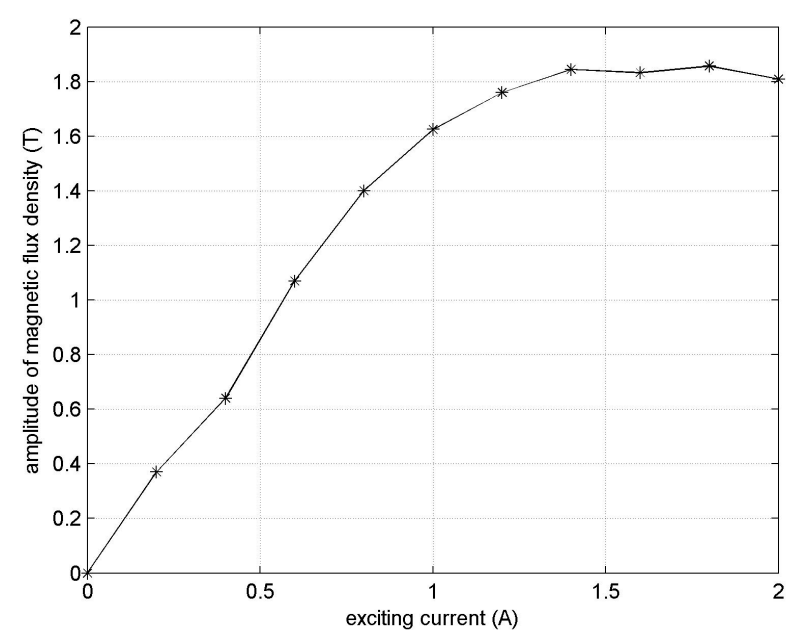

(b)

\subsubsection{Shielding Facility}

In the remote field eddy current testing system, a pick-up coil should be located about $2 \sim 3$ times the inner diameter away from an exciting coil. Taking into account the influence of wobble or off-center movement, the distance between pick-up coil and exciting coil always be $4 \sim 5$ times the inner diameter. The most effective method to reduce sensor length is to use a shielding facility to prevent the direct-coupled field from entering the pick-up coil. A combination of steel, copper and aluminum shown in Figure 7 is feasible and effective. Figure 16 shows the comparison of RFEC characteristic curves with and without a shielding facility. The remote field zone begins from about 1.1 times of inner diameter by using a shielding facility, as shown in Figure 16a. Taking into account the influence of wobble or off-center movement, the pick-up coil is located 1.7 times of inner diameter away from the exciting coil. 
Figure 16. RFEC Characteristic curves. (a) With shielding facility; (b) without shielding facility.

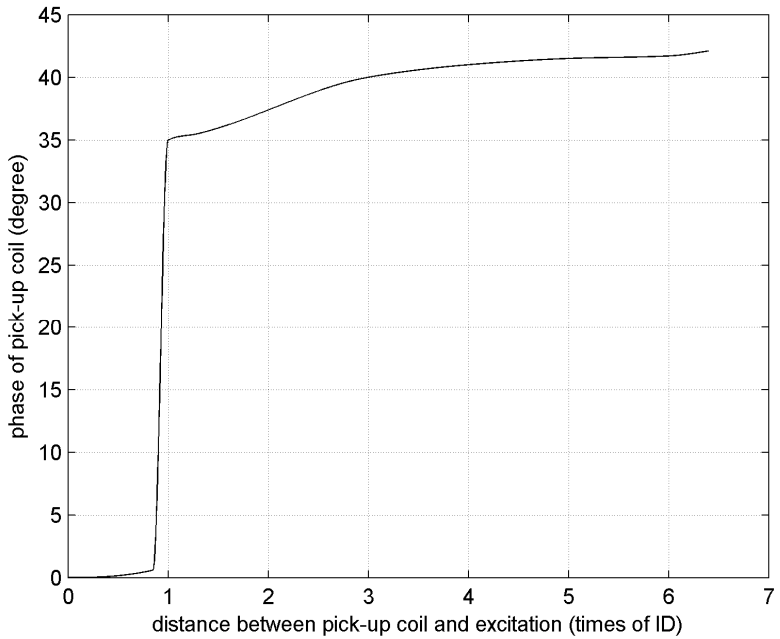

(a)

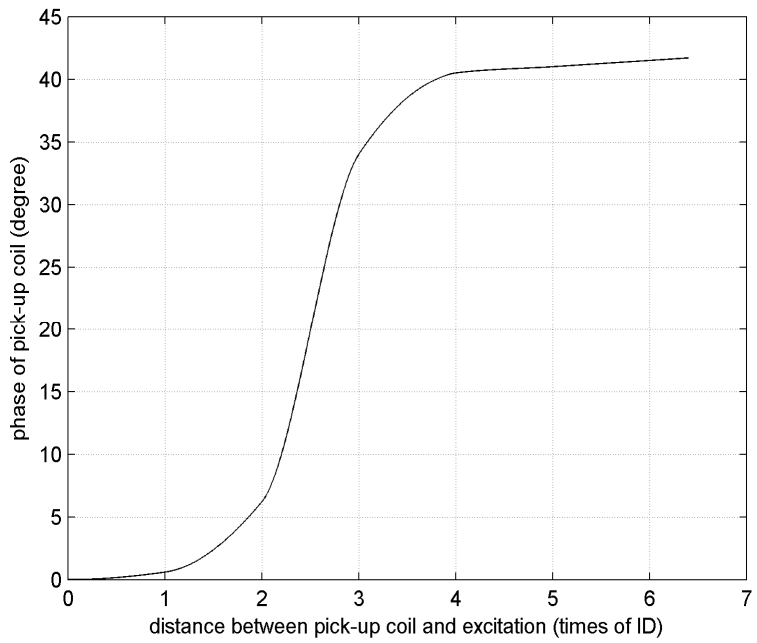

(b)

\section{Experimental Verification}

A ferromagnetic tube whose inner diameter is $70 \mathrm{~mm}$, outer diameter $82 \mathrm{~mm}$ and wall thickness $6 \mathrm{~mm}$ is used as a test specimen. Three types of defects are manufactured on the tube, as shown in Table 2. The above-mentioned self-differential mode pick-up coil, conventional pick-up coil, circumferential field pick-up coil and radial field pick-up coil are used to verify the detection sensitivity of orthogonal magnetic field excitation.

Table 2. Parameters of the test specimen.

\begin{tabular}{ccc}
\hline Type & Photography & Size \\
\hline Axial crack & Length: $10 \mathrm{~mm}$ \\
& Width: $0.5 \mathrm{~mm}$ \\
& & Depth: $15 \%, 20 \%, 40 \%$ and $60 \%$ of wall thickness \\
\hline & & Length: $10 \mathrm{~mm}$ \\
Circumferential crack & & Width: $0.5 \mathrm{~mm}$ \\
& & Depth: $15 \%, 20 \%, 40 \%$ and $60 \%$ of wall thickness \\
\hline & & Diameter $3 \mathrm{~mm}$ \\
& & Depth: $15 \%, 20 \%, 40 \%$ and $60 \%$ of wall thickness \\
\hline
\end{tabular}

\subsection{Self-Differential Mode Pick-Up Coil}

Figure 17 shows detection results when a self-differential mode pick-up coil based on an E-shape magnetic core is adopted. Although all of the defects whose depth are $15 \%$ wall thickness fail to be detected, the $20 \%$ wall thickness axial crack which cannot be detected by a conventional sensor can be detected and identified. At the same time, its detection sensitivity to different defects remains almost 
the same. For example, detection sensitivity to $60 \%$ wall thickness axial crack, circumferential crack and circular defect are $6.7^{\circ}$ phase difference, $6.2^{\circ}$ phase difference, and $9.6^{\circ}$ phase difference respectively, which can be seen from the peak change of Figure $17 \mathrm{a}-\mathrm{c}$, respectively.

Figure 17. Detection results. (a) Axial crack; (b) Circumferential crack; (c) Circular defect.

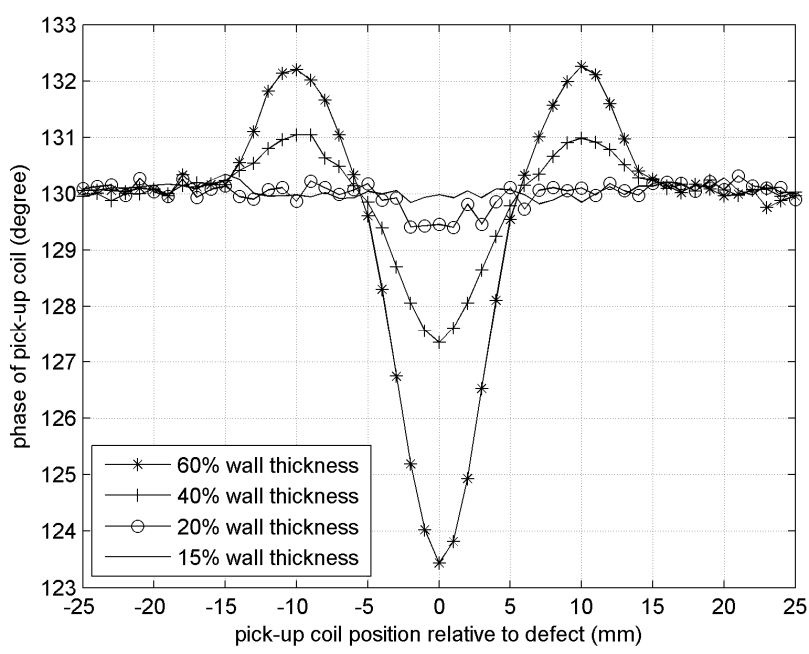

(a)

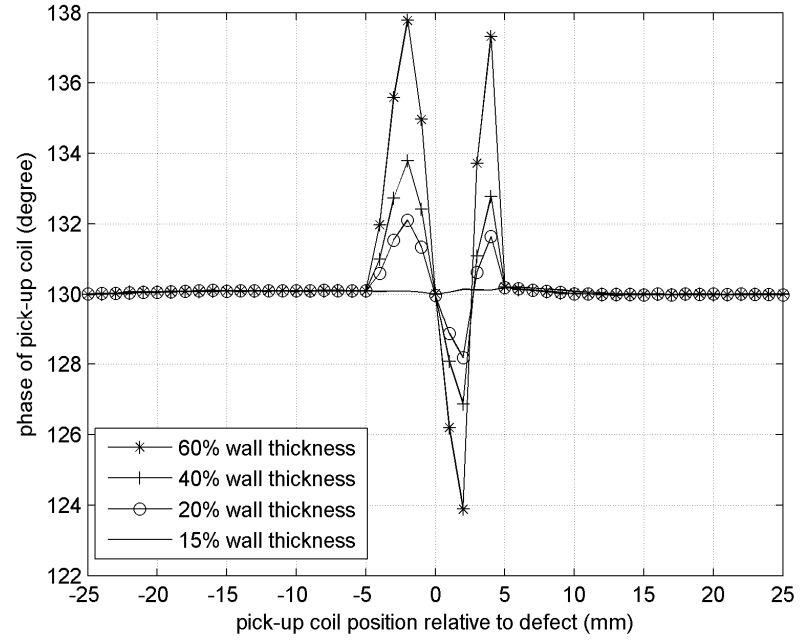

(b)

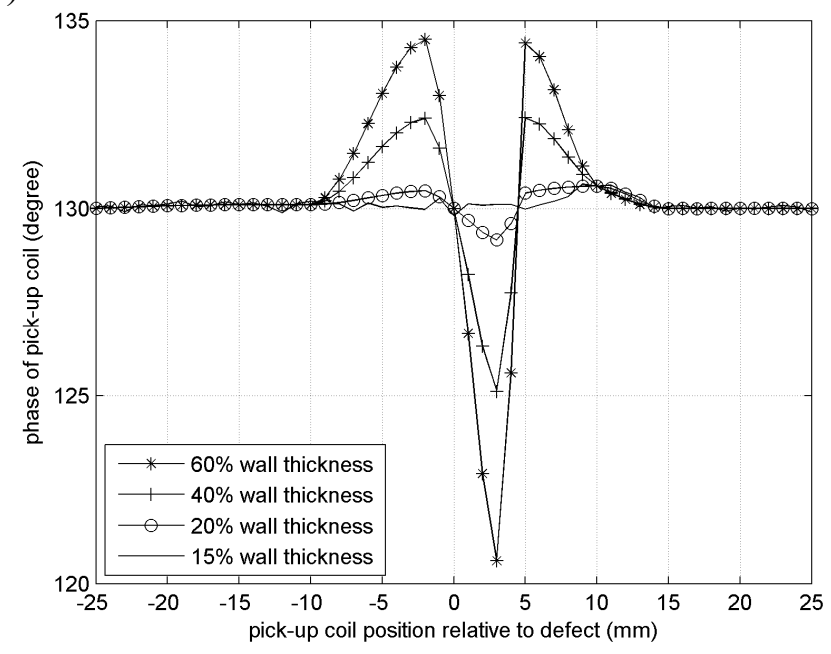

(c)

\subsection{Circumferential Field Pick-Up Coil}

Figure 18 shows detection results when a circumferential field pick-up coil based on a U-shape magnetic core is adopted. It is worth noting that a $15 \%$ wall thickness axial crack can be detected and identified clearly, but a $15 \%$ wall thickness circumferential crack and a circular defect fail to be detected. It means that this type of pick-up coil has enough sensitivity to detect axial cracks, but its detection sensitivity to circumferential cracks ( $5.1^{\circ}$ phase difference) is relatively lower than to axial cracks $\left(18.6^{\circ}\right.$ phase difference), which can be seen from the peak change of Figure 18. 
Figure 18. Detection results. (a) Axial crack; (b) Circumferential crack; (c) Circular defect.

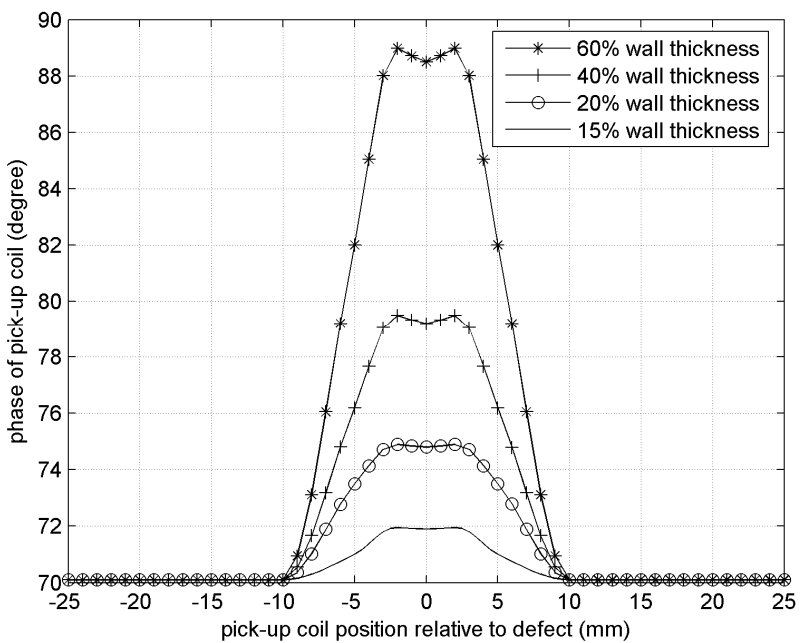

(a)

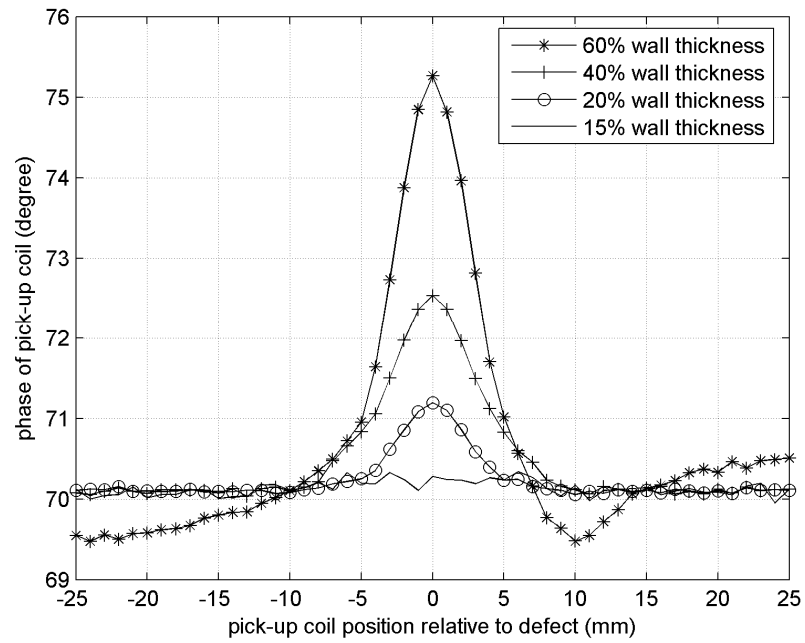

(b)

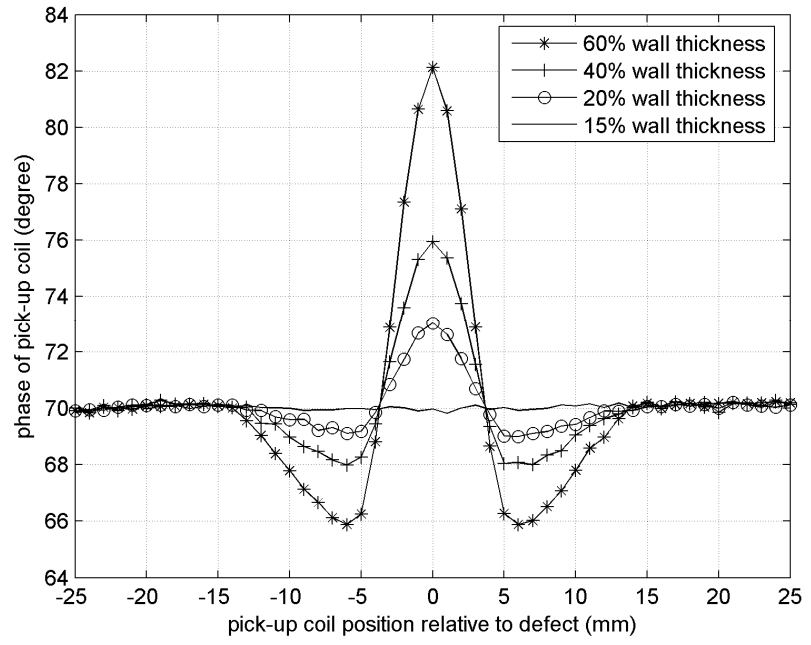

(c)

\subsection{Radial Field Pick-Up Coil and Conventional Pick-Up Coil}

When a radial field pick-up coil based on a rod magnetic core is adopted, all of the $15 \%$ wall thickness defects fail to be detected. Figure 19a shows the comparison of detection results for $20 \%$ wall thickness defects only. The detection results are similar to those of the self-differential mode pick-up coil, but the sensitivity is relatively lower, for instance, only $0.5^{\circ}$ phase difference for the $20 \%$ wall thickness axial crack. A conventional pick-up coil using a co-axial solenoid can only detect axial cracks whose width is $0.5 \mathrm{~mm}$ and depth more than $50 \%$ wall thickness. Figure $19 \mathrm{~b}$ shows the detection results of a 50\% wall thickness axial crack, circumferential crack and circular defect by a conventional pick-up coil. The detection sensitivity to circumferential cracks is much higher than that to axial cracks, and it is not easy to identify the axial crack from the background signal because the phase difference only is $0.3^{\circ}$. 
Figure 19. Detection results. (a) Radial field pick-up coil; (b) Conventional pick-up coil.

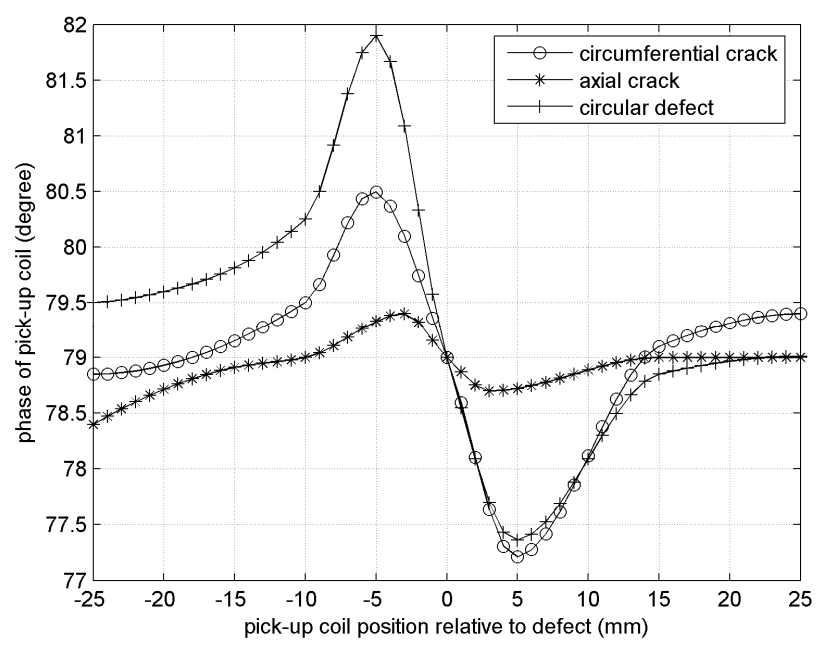

(a)

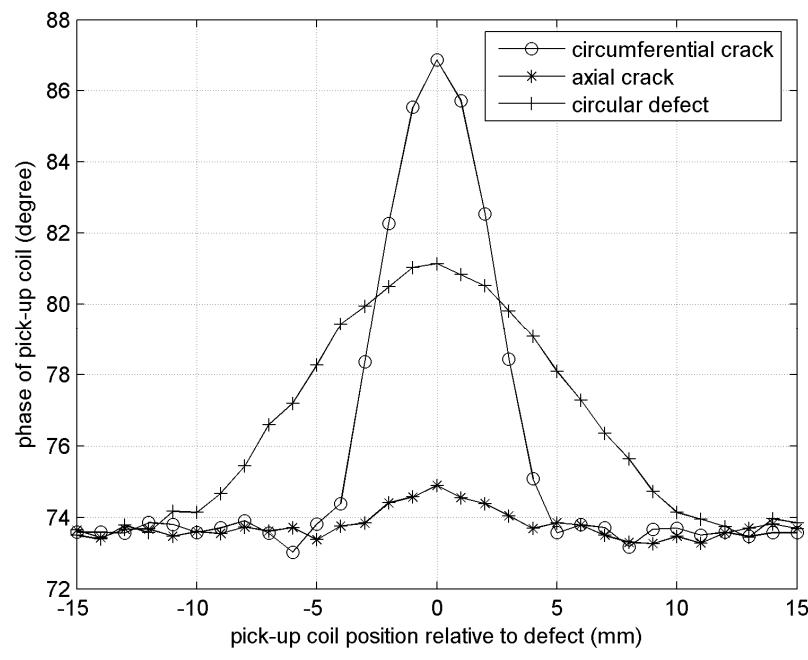

(b)

\section{Conclusions}

A conventional RFEC sensor has poor sensitivity to axial cracks, because it only uses axial magnetic field excitation. With orthogonal magnetic field excitation, its sensitivity to various types of defects can be improved effectively, especially to axial cracks. Adding a coaxial cylindrical conductor inside the conventional solenoid should be an appropriate configuration to generate the orthogonal magnetic field for tubular structures. When an orthogonal magnetic field excitation is adopted, different types of pick-up coils can be used to meet the requirements in different situations. For example, a self-differential mode pick-up coil can ensure similar sensitivity to various types of defects, a circumferential field pick-up coil can ensure enough high sensitivity to axial cracks, and a combination of them should be suitable for most occasions.

\section{Acknowledgments}

This work was support by The Chinese National Natural Science Fund (51107148) and The Natural Science Foundation of Shaanxi Province (2011JQ7006).

\section{Author Contributions}

Xiaojie $\mathrm{Xu}$ designed the sensor, compared the results and drafted the manuscript. Ming Liu executed the finite element simulation and analysis and revised the manuscript. Zhanbin Zhang performed the experiments, interpreted some results and read the manuscript critically and participated in its revision. Yueling Jia played a role in some experiments and simulation. All authors have read and approved the final manuscript.

\section{Conflicts of Interest}

The authors declare no conflict of interest. 


\section{References}

1. Javier, G.M.; Jaime, G.G.; Ernesto, V.S. Non-destructive techniques based on eddy current testing. Sensors 2011, 11, 2525-2565.

2. Noriyasu, K.; Souichi, U.; Satoshi, N.; Makoto, O.; Noboru, J. Remote field eddy current testing for steam generator inspection of fast reactor. Nucl. Eng. Des. 2011, 241, 4643-4648.

3. Xu, X.J.; Luo, F.L. Optimal sensor design and digital signal processing techniques for remote field eddy current testing. Insight 2006, 48, 421-425.

4. Atherton, D.L. Remote field eddy current inspection. IEEE. Trans. Magn. 1995, 31, 4142-4147.

5. Smith, S.; Atherton, D.L. Longitudinal AC interactions with axial slits in steel pipes. Res. Nondestr. Eval. 1996, 7, 203-214.

6. Kim, L.; Udpa, S.S. Remote field eddy current testing for detection of stress corrosion cracks in gas transmission pipelines. Mater. Lett. 2004, 58, 2102-2104.

7. Kim, Y.J.; Lee, S.S. Eddy current probes of inclined coils for increased detectability of circumferential cracks in tubing. NDT E Int. 2012, 49, 77-82.

8. Xin, J.J.; Lei N.G.; Udpa, L.; Udpa, S.S. Rotating field eddy current probe with bobbin pickup coil for steam generator tubes inspection. NDT E Int. 2013, 54, 45-55.

9. Capobinaco, T.E. Rotating field eddy current probe for characterization of cracking in non magnetic tubing. Rev. Progress QNDE 1999, 18, 449-454.

10. Grimberg, R.; Udpa, L.; Udpa, S.S. A novel rotating magnetic field eddy current transducer for the examination of fuel channels in PHWR nuclear power plants. Rev. Progress QNDE 2005, 24, 471-478.

11. Savin, A.; Udpa, L.; Steigmann, R.; Bruna, A.; Grimberg, R.; Udpa, S.S. Remote field eddy current control using rotating magnetic field transducer. Application to pressure tubes examination. Electromagn. Nondestruct. Eval. 2008, 31, 249-256.

12. Chen, Z.M.; Mihai, R.; Kenzo, M. Three dimensional simulation of remote field ECT using the Ar method and a new formula for signal calculation. Res. Nondestr. Eval. 2005, 16, 35-53.

13. Nor, T.Y.; Stephaney, P.; Kazue, M. Numerical modeling of general cracks from the viewpoint of eddy current simulations. NDT E Int. 2007, 40, 577-583.

14. Cheng, J.; Qiu, J.H.; Takagi, T.; Uchimoto, T.; Hu, N. Numerical analysis of correlation between fibre orientation and eddy current testing signals of carbon-fibre reinforced polymer composites. Int. J. Appl. Electromagn. 2012, 39, 251-259.

15. Cheng, J.; Ji, H.L.; Qiu, J.H.; Takagi, T.; Uchimoto, T.; Hu, N. Novel electromagnetic modeling approach of carbon fiber-reinforced polymer laminate for calculation of eddy currents and eddy current testing signals. J. Compos. Mater. 2014, doi:10.1177/0021998314521475.

16. Hector, S.L.; Michael, P.; Stuart, C. Eddy current simulation in thick cylinders of finite length induced by coils of arbitrary geometry. J. Magn. Reson. Imaging 2010, 207, 251-261.

17. Zhang, Y.J.; Atherton, D.L. Finite element analysis for remote field eddy current responses from near and far side cracks. Res. Nondestr. Eval. 1998, 9, 163-169.

18. Wang, P.; Fu, Z.B.; Ding, T.H. A frameless eddy current sensor for cryogenic displacement measurement. Sens. Actuators A Phys. 2010, 159, 7-11. 
19. Rolicz, P. Eddy currents generated in a system of two cylindrical conductors by a transverse alternating magnetic field. Electr. Power Syst. Res. 2009, 79, 295-300.

20. Mao, X.F.; Lei, Y.Z. Analysis of eddy current interaction between a parallel coil and a ferromagnetic pipe with remanence. NDT E Int. 2013, 60, 121-126.

21. Luis, S.R.; Telmo, G.S.; Pedro, M.R.; Pedro, V.; Moisés, P. A differential planar eddy currents probe: Fundamentals, modeling and experimental evaluation. NDT E Int. 2012, 51, 85-93.

22. Robaina, R.R.; Héctor, T.A.; Plaza, J.A. Planar coil-based differential electromagnetic sensor with null-offset, Sens. Actuators A Phys. 2010, 164, 15-21.

23. Sun, Y.S.; Dennis, R.; Harry, Z. New advances in detecting cracks in raised-head fastener holes using rotational remote field eddy current technique. In Proceedings of the ASNT Fall Conference, Columbus, OH, USA, 17-21 October 2005.

(C) 2014 by the authors; licensee MDPI, Basel, Switzerland. This article is an open access article distributed under the terms and conditions of the Creative Commons Attribution license (http://creativecommons.org/licenses/by/4.0/). 